\title{
LEVANTAMENTO FLORÍSTICO DAS ESPÉCIES ARBÓREAS DE UM TRECHO DE MATA CILIAR NO MUNICÍPIO DE ASTORGA, PARANÁ, BRASIL
}

\author{
Letícia Mônica Garcia* \\ Mariza Barion Romagnolo**
}

RESUMO: O presente trabalho teve como objetivo conhecer a composição florística e estágio sucessional das espécies arbóreas que compõem as margens da mata ciliar do Ribeirão da Içara (2309'51.74’'S e 51³9'21.60”W), no município de Astorga, na região norte do Estado do Paraná. O clima da região é classificado como Cfa, e altitude média de $532 \mathrm{~m}$. A área de estudo apresenta $0,5 \mathrm{ha}$, pertence ao domínio de Floresta Estacional Semidecidual, consiste em um trecho de mata ciliar formado por uma vegetação nativa com agrupamentos densos de árvores, cipós (trepadeiras), pouca vegetação rasteira e reflorestamento. A ocupação do solo do entorno é a pecuária e a produção de culturas de cana-de-açúcar e laranja. As coletas de material botânico foram realizadas através de expedições mensais com duração de três dias no período de dezembro de 2010 a março de 2011. Foram amostrados os indivíduos arbóreos em estágio reprodutivo, os quais foram incorporados ao acervo do HUEM. Algumas espécies foram coletadas apenas suas partes vegetativas. O material coletado foi identificado com auxílio de bibliografia específica e por comparação com o material do acervo do HUEM, seguindo o sistema APG III. As espécies foram classificadas quanto ao estágio sucessional através de consulta a bibliografias específicas e observações de campo, sendo que as exóticas e as indeterminadas não foram consideradas para esta análise. Foram registradas 84 espécies reunidas em 77 gêneros e 28 famílias, das quais seis foram identificadas apenas em nível de gênero, quatro ao nível de família e uma de família indeterminada. Fabaceae apresentou o maior número de espécies (23), seguida de Myrtaceae com seis, Malvaceae e Meliaceae com cinco, Anacardiaceae, Bignoniaceae, Euphorbiaceae e Sapindaceae com quatro, Rutaceae com três. Nestas famílias estão contidos $69,05 \%$ do número de espécies. O gênero com maior número de espécies foi o Machaerium (três). Quanto ao estágio sucessional, 35,93\% das espécies pertencem à classe sucessional pioneira, 32,81\% secundária inicial, 20,31\% secundária tardia e 10,44\% clímax. Este resultado, com predomínio de espécies pioneiras e secundárias, mostra que existe uma substituição gradual das espécies, o que possivelmente pode estar relacionado com a retirada de espécies de importância comercial.

\footnotetext{
"Discente da Especialização em Meio Ambiente e Recursos Hídricos da Faculdade de Filosofia Ciências e Letras de Mandaguari - FAFIMAN, Mandaguari, (PR), Brasil; E-mail: leticia1_monica@hotmail.com

*** Docente do Curso de Ciências Biológicas da Universidade Estadual de Maringá - UEM, Maringá (PR), Brasil.
} 
PALAVRAS-CHAVE: Córrego Água do Içara; Estágio Sucessional; Vegetação Nativa.

\section{FLOWER SURVEY OF TREE SPECIES OF RIPARIAN VEGETATION IN ASTORGA, BRAZIL}

ABSTRACT: The floristic composition and successional stage of tree species in riparian vegetation of the Ribeirão da Içara (2309'51.74'S and 51'39'21.60'W) in the municipality of Astorga in the northern region of the state of Paraná, Brazil, are analyzed. Climate is Cfa and average altitude is $532 \mathrm{~m}$. The 0.5 ha area under analysis belongs to the Semideciduous Seasonal Forest and consists of a stretch of riparian vegetation formed by native vegetation with dense tree groups, creepers, ground vegetation and reforestation. Surrounding ground is occupied by livestock and the production of sugar cane and orange trees. Botanic material was collected by 3-day monthly expeditions between December 2010 and March 2011. Tree specimens in the reproduction stage were sampled and voucher specimens were incorporated to the collection of the State University of Maringá. Only the vegetal parts of some species were collected and the material was identified by specific bibliography and compared with specimens at the university, following the APG III system. Species were classified with regard to their successional stage by specific bibliography and field observations, although exotic and indeterminate plants were not taken into account in current analysis. Eighty-four species, with 77 genera and 28 families, were registered. Six were identified at genus level, four at family level and one family was undetermined. The Fabaceae had the highest number of species (23), followed by Myrtaceae (6), Malvaceae and Meliaceae (5), Anacardiaceae, Bignoniaceae, Euphorbiaceae and Sapindaceae (4), Rutaceae (3). Further, 69.05\% of species belong to these families. Machaerium (3) was the genus with the highest number of species. With regard to the successional stage, $35.93 \%$ were species of the pioneer succession class; $32.81 \%$ initial secondary class; $20.31 \%$ late secondary class and $0.44 \%$ climax class. Results, featuring predominantly pioneer and secondary species, show a gradual replacement of species, perhaps related to the removal of commercially relevant species.

KEY WORDS: Água do Içara Stream; Successional Stage; Native Vegetation. 


\section{INTRODUÇÃO}

O Brasil apresenta diversidade de ecossistemas florestais por ter uma grande área física, diversidade de climas e solos em seu território (LEITÃO FILHO, 1987). $\mathrm{E}$, devido à sua localização geográfica e sua extensão de $8.511 .965 \mathrm{~km}^{2}$ apresenta seis biomas: Amazônia, Cerrado, Caatinga, Pantanal, Pampa e Mata Atlântica (IBGE, 2004). A Mata Atlântica é um tipo de floresta tropical que tem status de patrimônio nacional garantido pela Constituição Brasileira de 1988, em seu artigo 225, e pela Lei 11.428 de 2006 (BRASIL, 2010). Tal bioma já cobriu cerca de 15\% do território nacional e, com o desmatamento, foi perdendo terreno, hoje reduzido a $7 \%$ de sua configuração original (SOS MATA ATLÂNTICA, 2010).

As formações vegetais presentes no Estado pertencem aos seguintes tipos: Floresta Ombrófila Densa, Floresta Ombrófila Mista, Floresta Estacional Semidecidual, Savana e Estepe (RODERJAN; KUNIUOSHI; GALVÃO, 1998). E entre estas a Floresta Estacional Semidecidual foi a mais prejudicada por ações antrópicas, restando aproximadamente $4 \%$ da cobertura, pois o Paraná era originalmente coberto por aproximadamente $84,7 \%$ de formações florestais, e hoje encontram-se em condições muito precárias (FONTOURA, 2007; SOS MATA ATLÂNTICA, 2010).

Fragmentação florestal é o processo pelo qual grandes áreas são transformadas em pequenas manchas, ou seja, ocorre a ruptura na continuidade de habitats naturais, que pode ocasionar a quebra do patrimônio genético entre populações e de cada espécie (METZGER, 2003). Sendo exemplo do processo de degradação e fragmentação florestal, os poucos remanescentes preservados possuem grande valor ecológico e taxonômico (DEL QUIQUI et al., 2007).

No Paraná o processo de desenvolvimento baseado no uso intensivo de terra para agricultura/pecuária, alagamentos de áreas para abastecimento de água, geração de energia elétrica e expansão urbana, reduziu as grandes áreas contínuas de cobertura florestal nativa (FONTOURA, 2007). O Estado é formado por regióes fitogeográficas resultantes de peculiaridades geomorfológicas, pedológicas e climáticas, condição pelo qual sofreu intenso processo de redução e fragmentação da vegetação (CAMPOS, 2006). Assim, a situação do norte do Estado do Paraná é 
semelhante à de outros Estados do Brasil, já que a maior parte das florestas foi quase que totalmente dizimada, podendo ou não ter uma estrutura genética mínima para garantir a autosustentação (SOARES-SILVA; SILVA; CAVALHEIRO, 2001).

Devido a estes fatos, há ausência principalmente das matas ciliares, que são a formação vegetal que ocupa as margens dos rios, córregos, lagos, lagoas, olhos d'água, represas e nascentes, sendo considerada pelo Código Florestal Federal (Lei 4.771, de 15 de setembro de 1965), como Área de Preservação Permanente (APP) (BRASIL, 2010).

Mata ciliar também é conhecida como mata de galeria, mata de várzea, vegetação ou floresta ripária (SEMA, 2009). Atua protegendo as nascentes de água e os animais aquáticos, evitando a erosão das margens, funcionando como filtro aos agentes poluidores, servindo de refúgio às aves e animais, favorecendo a criação de corredores de biodiversidade para o movimento da fauna, assim como para a dispersão vegetal, promovendo o repovoamento faunístico das matas artificiais, fornece o alimento para a fauna aquática e silvestre ribeirinha preservando e recuperando a biodiversidade da flora, é de grande importância para a preservação da qualidade e quantidade dos recursos hídricos (DURIGAN; SILVEIRA, 1999; ALCALÁ et al., 2006; MARTINS, 2005; FUNVERDE, 2009; GASPARINO et al., 2006).

Dessa forma, levantamentos florísticos em remanescentes de florestas ciliares, realizados em diferentes regiões do Brasil, mostram que essas áreas são diversas quanto à composição e estrutura florística e fitossociológica, como resultado da heterogeneidade ambiental que apresentam (SANCHEZ et al.,1999). Assim, o conhecimento e o entendimento da complexa dinâmica que envolve as florestas podem ser compreendidos através de levantamento florístico, sendo que a identidade das espécies é o começo para a compreensão de todo o processo de um ecossistema (MARANGON; SOARES; FELICIANO, 2003).

Dentro deste contexto, o presente trabalho teve como objetivo descrever a composição florística e o estágio sucessional das espécies arbóreas que compõem respectivamente as margens esquerda e direita da mata ciliar do Ribeirão da Içara, no município de Astorga, na região norte do Estado do Paraná. 


\section{MATERIAL E MÉTODOS}

\section{1 ÁREA DE ESTUDO}

A área de estudo apresenta 0,5ha e compreende a margem direita e esquerda de um trecho de mata ciliar, pertencente a propriedades rurais particulares, nos sítios São Pedro e São José, localizados a 2309'51.74’'S e 51³9'21.60”'W com altitude de aproximadamente 532m (Figura 1), localizada nas margens do Ribeirão da Içara, no distrito de Içara, no município de Astorga, Paraná (Figura 1).
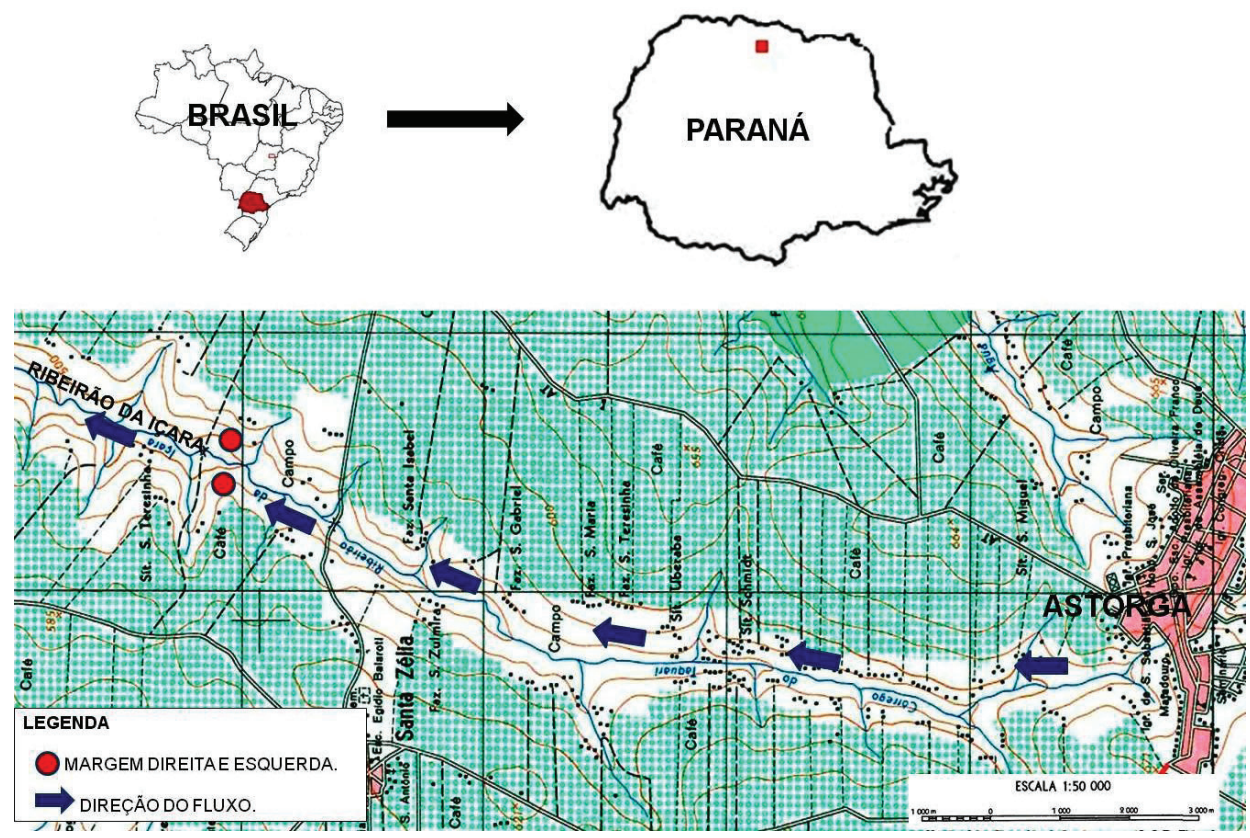

Figura 1: Localização da área de estudo. Margens do Ribeirão da Içara, distrito de Içara, município de Astorga, Paraná, Brasil.

Fonte: IBGE (junho, 2011); Modificado por: GARCIA, L. M., 2011.

De acordo com a classificação de Köppen o clima é do tipo Cfa - Clima Subtropical Mesotérmico, com média do mês mais quente superior a $22^{\circ} \mathrm{C}$, e no mês mais frio inferior a $18^{\circ} \mathrm{C}$, sem estação seca definida, verão quente e geadas menos frequentes (PARANÁ, 2007). 
O solo da região, de acordo com sua formação geológica, pode ser identificados como basáltico com solo laterítico, popularmente conhecido por Terra Roxa, de cor vermelho-arroxeada e solos lateríticos erodidos, e também Arenito Caiuá com solos lateríticos arenosos, de cor vermelho-arroxeada e solos lateríticos lexiviados (lavados) e podozolizados (acinzentados) dos declives erodidos (EMBRAPA, 1999).

A vegetação florestal da região pertence ao domínio da Floresta Estacional Semidecidual (IBGE, 1992). Apresenta vegetação formada por agrupamentos densos com árvores, cipós (trepadeiras) e pouca vegetação rasteira. A ocupação do solo do entorno é a pecuária e a produção de culturas de cana-de-açúcar e laranja.

O levantamento florístico das espécies arbóreas foi realizado nas margens direita e esquerda do Ribeirão da Içara, sendo a margem direita composta por espécies nativas da área e outras provenientes de recomposição da mata ciliar, e a margem esquerda por espécies nativas, sendo que esta passou por processo natural de regeneração.

\subsection{LEVANTAMENTO FLORÍSTICO}

Para o levantamento florístico foram realizadas expedições ao trecho de mata ciliar, distribuídas entre os meses de dezembro de 2010 a março de 2011. As coletas foram realizadas por meio de caminhadas, acompanhadas com o proprietário, que contribuiu com informações sobre as espécies provenientes do reflorestamento e as nativas da regeneração natural.

Foram amostrados os indivíduos arbóreos em estágio reprodutivo. Durante as coletas utilizou-se os seguintes equipamentos: tesoura de poda alta, cabo de 12 m, tesoura de poda manual, fita adesiva, sacos plástico de 20 litros, caneta, câmera fotográfica digital, prancheta para anotar observações. A cada coleta foram anotadas informações sobre a planta, como por exemplo: altura, presença de botões, flores e frutos, bem como odor e coloração dos mesmos.

O material coletado foi etiquetado, acondicionado em sacos plásticos e transportado para o Laboratório de Botânica do Centro Universitário de Maringá, onde foram herborizados de acordo com os métodos usuais (FIDALGO; BONONI, 
1989). Após a identificação das espécies, as exsicatas foram incorporadas ao HUEM. A identificação de famílias, gêneros e espécies foi realizada seguindo o sistema de classificação de APG III (2009), consulta às bibliografias especializadas, e sites como: Neotropical Herbarium Specimes (2011) e FLORA DIGITAL - Laboratório de Fitoecologia e Fitogeografia (2008).

A correção dos nomes científicos e dos autores foi realizada por meio dos sites The Royal Botanic Gardens Kew (IPNI, 2011) e do Missouri Botanical Garden, St. Louis (MOBOT, 2010). E para verificar as espécies com ameaça de extinção foi consultada a lista vermelha da flora ameaçada de extinção do IAP (2011) e da IUCN (2011).

As espécies foram classificadas quanto à categoria sucessional em: Pioneiras (P), Secundárias Iniciais (SI), Secundárias Tardias, (ST) e Clímax (C), sensu Budowski (1965) de acordo com observações de campo e consulta à literatura (FERRETTI et al., 1995; BARBOSA, 2000; BORGHI et al., 2004; CARPANEZZI; CARPANEZZI, 2006; CARVALHO, 2003; GANDOLFI, 1991; KAGEYAMA, 1992; VACCARO et al., 1999; LORENZI, 2000; 2008; 2009a; 2009b). As exóticas e as indeterminadas não foram consideradas para esta análise.

\section{RESULTADOS E DISCUSSÃO}

No levantamento florístico foram registrados 84 táxons, pertencentes a 28 famílias, distribuídas em 76 gêneros, sendo que 79 táxons foram identificados somente até o nível de gênero (Tabela 1). 
Tabela 1. Relação de famílias, gêneros e espécies coletadas de dezembro de 2010 a março de 2011, com seu respectivo nome popular, área de ocorrência, estágios sucessionais e classificação das espécies de extinção da lista vermelha. Ribeirão da Içara, distrito de Içara, município de Astorga, Paraná. (ÁREA $1=$ margem direita; ÁREA 2 = margem esquerda; REFLO = espécies do reflorestamento; $\mathrm{CS}=$ categoria sucessional; $\mathrm{P}=$ pioneiras; $\mathrm{SI}=$ secundária inicial; $\mathrm{ST}=$ secundária tardia; e $\mathrm{C}=$ clímax).

(continua)

\begin{tabular}{lcccccc}
\hline \multirow{2}{*}{ FAMÍLIAAESPÉCIE } & NOME & ÁREA & ÁREA & \multirow{2}{*}{ REFLO } & \multirow{2}{*}{ C $S$} & LISTA \\
& POPULAR & 1 & 2 & & & VERMELHA \\
\hline
\end{tabular}

\section{ANACARDIACEAE}

$\begin{array}{lllllr}\text { Astronium graveolens Jacq. } & \text { guaritá } & \mathrm{X} & & \mathrm{X} & \mathrm{ST} \\ \text { Mangifera } \text { indica } \mathrm{L} . & \text { mangueira } & \mathrm{X} & & \mathrm{X} & \\ \text { Schinus terebinthifolius Raddi } & \text { aroeira-vermelha } & \mathrm{X} & \mathrm{X} & \mathrm{X} & \mathrm{P} \\ \text { Spondias dulcis G.Forst. } & \text { cajá-manga } & \mathrm{X} & & \mathrm{X} & \end{array}$

\section{ANNONACEAE}

Rollinia mucosa Baill. conde

$\mathrm{X}$ $\mathrm{X}$

Rollinia sylvatica (A. St.-Hil.) araticum $\mathrm{X}$ ST Mart.

\section{APOCYNACEAE}

Tabernaemontana catharinensis leiteiro Steud.

$\mathrm{X} \quad \mathrm{X} \quad \mathrm{P}$

\section{BIGNONIACEAE}

Jacaranda micrantha Cham. jacarandá

Tabebuia heptaphylla (Vell.) ipê-roxo

Toledo

Tecoma stans Juss.

amarelinho

$\begin{array}{cccc} & \mathrm{X} & & \mathrm{P} \\ \mathrm{X} & & \mathrm{X} & \mathrm{SI}\end{array}$

Indeterminada

$\mathrm{X}$

$\mathrm{X}$

$\mathrm{P}$

BORAGINACEAE

Cordia americana Steud.

guaiuvira

$\mathrm{X}$

X

C

Cordia ecalyculata Vell.

café-de-bugre

$\mathrm{X}$

SI

\section{CANNABACEAE}

Celtis iguanaea (Jacq.) Sarg

esporão-de-galo

Trema micrantha Blume

grandiúva

$\begin{array}{llll} & \mathrm{X} & & \mathrm{SI} \\ \mathrm{X} & \mathrm{X} & \mathrm{X} & \mathrm{P}\end{array}$


(continua)

\section{CELASTRACEAE}

$\begin{array}{lllll}\text { Maytenus aquifolium Mart. } & \text { espinheira-santa } & \mathrm{X} & \mathrm{X} & \text { ST }\end{array}$

\section{ERYTHROXYLACEAE}

Erythroxylum sp

$\mathrm{X} \quad \mathrm{X}$

\section{EUPHORBIACEAE}

Alchornea triplinervia Müll.Arg. tapiá

Actinostemon concolor Müll.Arg. laranjeira do mato

Croton floribundus Spreng. capixingui

Sebastiania commersoniana branquilho

$\begin{array}{cccc}\text { X } & \text { X } & \text { X } & \text { P } \\ & \text { X } & & \text { ST } \\ & & & \\ \text { X } & \text { X } & & \text { P } \\ & \text { X } & & \text { SI }\end{array}$

(Baill.) L.B.Sm. \& R.J.Downs

\section{FABACEAE-}

\section{CAESALPINIOIDEAE}

\begin{tabular}{|c|c|c|c|c|}
\hline Baubinia sp & & $\mathrm{X}$ & & $\mathrm{X}$ \\
\hline $\begin{array}{l}\text { Caesalpinia peltophoroides } \\
\text { Benth. }\end{array}$ & sibipiruna & $\mathrm{X}$ & & $\mathrm{X}$ \\
\hline Holocalyx balansae Micheli & $\begin{array}{l}\text { alecrim-de- } \\
\text { campinas }\end{array}$ & & $\mathrm{X}$ & \\
\hline Peltophorum dubium Taub. & canafístula & $\mathrm{X}$ & $\mathrm{X}$ & $\mathrm{X}$ \\
\hline Pterogyne nitens Tul. & amendoim & $\mathrm{X}$ & & \\
\hline $\begin{array}{l}\text { Schizolobium parabyba (Vell.) } \\
\text { Blake }\end{array}$ & guapuruvu & $\mathrm{X}$ & & $\mathrm{X}$ \\
\hline $\begin{array}{l}\text { Senna multijuga (L.C.Richard) } \\
\text { H.S.Irwin \& Barneby }\end{array}$ & pau-cigarra & $\mathrm{X}$ & $\mathrm{X}$ & \\
\hline Indeterminada & & & $\mathrm{X}$ & \\
\hline
\end{tabular}

\section{FABACEAE- FABOIDEAE}

Dalbergia frutescens Britton rabo-de-bugio

$\begin{array}{lll} & \mathrm{X} & \mathrm{SI} \\ \mathrm{X} & \mathrm{X} & \mathrm{P}\end{array}$

$\begin{array}{lllll}\text { Lonchocarpus campestris Mart. rabo-de-bugio } & \mathrm{X} & \mathrm{X} & \mathrm{P}\end{array}$ ex Benth. 
(continua)

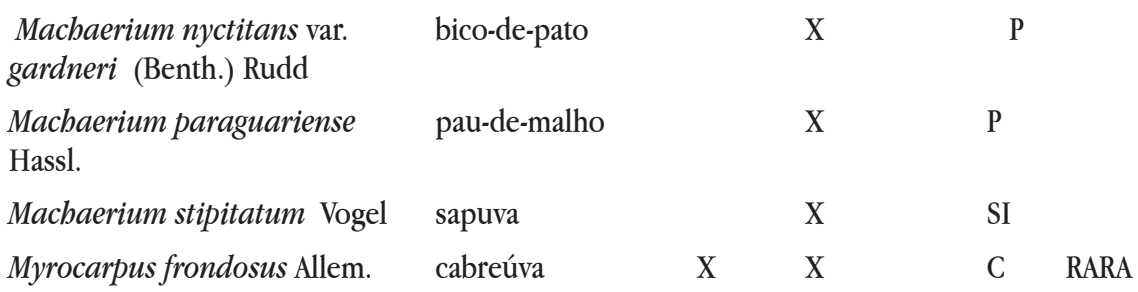

\section{FABACEAE- MIMOSOIDEAE}

Acacia polyphylla DC.

monjoleiro

Albizia niopoides (Spruce ex

Benth.) Burkart

Calliandra foliolosa Benth. caliandra

ingá

Inga edulis Mart.

angico-branco

$\begin{array}{llll} & \mathrm{X} & & \text { SI } \\ \mathrm{X} & \mathrm{X} & \mathrm{X} & \text { ST }\end{array}$

Inga sp.

leucena

Leucaena leucocephala (Lam.)

de Wit

Mimosa sp

$\mathrm{X}$

$\mathrm{X}$

C

Parapiptadenia rigida (Benth.) angico-vermelho $\mathrm{X}$ $\mathrm{X}$

$\mathrm{X} \quad \mathrm{P}$

Brenan

\section{LAURACEAE}

Nectandra megapotamica Mez canela

X $\quad \mathrm{X}$

SI

Indeterminada

$\mathrm{X}$

$\mathrm{X}$

\section{MALVACEAE}

Bastardiopsis densiflora Hassl. louro-branco

Ceiba speciosa (A.St.-Hil., A.Juss. paineira

\& Cambess.) Ravenna

Guazuma ulmifolia Wall.

Heliocarpus popayanensis Kunth.

Luebea divaricata Mart. mutambo

algodoeiro

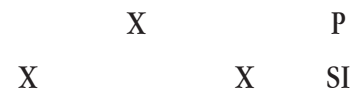

açoita-cavalo

$\mathrm{X}$

$\mathrm{X}$

X SI

\section{MELIACEAE}

$\begin{array}{llll}\text { Azadirachta indica A.Juss. } & \text { nim } & \text { X } & \text { X }\end{array}$ 
(continua)

\begin{tabular}{|c|c|c|c|c|c|c|}
\hline Cedrela fissilis Vell. & cedro & $\mathrm{X}$ & & $\mathrm{X}$ & $\mathrm{C}$ & EM PERIGO \\
\hline Melia azedarach L. & santa-barbara & $\mathrm{X}$ & $\mathrm{X}$ & & & \\
\hline Trichilia catigua A.Juss. & catiguá & & $\mathrm{X}$ & & ST & \\
\hline Trichilia elegans A.Juss. & catiguá & & $\mathrm{X}$ & & ST & \\
\hline
\end{tabular}

\section{MORACEAE}

Ficus sp

$\begin{array}{lll} & \mathrm{X} & \text { SI } \\ \text { amoreira-branca } & \mathrm{X} & \mathrm{P}\end{array}$

Maclura tinctoria D.Don ex amoreira-branca II

Steud.

\section{MYRTACEAE}

Campomanesia guazumifolia sete-capotes
Blume

Campomanesia xanthocarpa gabiroba $\quad \mathrm{X} \quad \mathrm{X} \quad \mathrm{C}$

O.Berg

Eucalyptus sp

Eugenia uniflora L.

Psidium guajava L.

Syzygium cumini (L.) Skeels

$\begin{array}{lllll} & \mathrm{X} & & & \\ \text { pitanga } & \mathrm{X} & \mathrm{X} & & \mathrm{C} \\ \text { goiaba-vermelha } & \mathrm{X} & \mathrm{X} & \mathrm{X} & \\ \text { jambolão } & \mathrm{X} & & \mathrm{X}\end{array}$

\section{NYCTAGINACEAE}

Bougainvillea glabra Choisy

primavera

X $\quad \mathrm{X}$

ST

\section{PHYTOLACCACEAE}

$\begin{array}{lllll}\text { Gallesia integrifolia (Spreng.) pau-d'alho } & \text { X } & \text { X } & \text { ST } \\ \text { Harms } & & & \end{array}$

$\begin{array}{llll}\text { Phytolacca dioica L. } & \text { cebolão } & \mathrm{X} & \text { SI }\end{array}$

\section{POLYGONACEAE}

$\begin{array}{lllll}\text { Ruprechtia laxiflora Meisn. } & \text { marmeleiro } & \mathrm{X} & \mathrm{X} & \text { ST }\end{array}$

\section{PROTEACEAE}

$\begin{array}{llll}\text { Grevillea robusta A.Cunn. } & \text { grevílea } & \mathrm{X} & \mathrm{X}\end{array}$ 
(continua)

\section{RHAMNACEAE}

Hovenia dulcis Thunb.

uva-japonesa

X

X

\section{RUTACEAE}

$\begin{array}{lllll}\text { Metrodorea nigra A.St.-Hil. } & \text { carrapateira } & & \text { X } & \text { SI } \\ \text { Pilocarpus pennatifolius Lem. } & \text { jaborandi } & \text { X } & & \text { P } \\ \text { Indeterminada } & & \text { X } & & \end{array}$

\section{RUBIACEAE}

Randia ferox DC.

limão-do-mato

X

SI

\section{SALICACEAE}

Casearia sylvestris $\mathrm{Sw}$.

guaçatunga

X

SI

\section{SAPINDACEAE}

$\begin{array}{lll}\text { Allophylus edulis Radlk. ex } \quad \text { vacum } & \mathrm{X} & \mathrm{P}\end{array}$ Warm.

$\begin{array}{llll}\text { Cupania vernalis Cambess. } & \text { camboatá } & \text { X } & \text { SI }\end{array}$

$\begin{array}{llll}\text { Diatenopteryx sorbifolia Radlk. maria preta } & \text { X } & \text { ST }\end{array}$

Matayba elaeagnoides Radlk. camboatá $\quad$ X $\quad$ SI

\section{SAPOTACEAE}

Chrysophyllum gonocarpum guatambu

$\mathrm{X} \quad \mathrm{ST}$

Engl.

\section{SOLANACEAE}

$\begin{array}{lllll}\text { Solanum granuloso-leprosum fumo-bravo } & \mathrm{X} & \mathrm{P} & \text { BAIXO }\end{array}$

Dunal

RISCO

\section{URTICACEAE}

$\begin{array}{lllll}\text { Boebmeria caudata } \mathrm{Sw} . & \text { urtiga-mansa } & & \mathrm{X} & \mathrm{P} \\ \text { Cecropia glaziovii Snethl. } & \text { embaúba } & \mathrm{X} & & \mathrm{P}\end{array}$


(conclusão)

\section{INDETERMINADA}

Indeterminada

$\mathrm{X}$

Comparando as áreas 1 e 2, foram registradas 28 espécies provenientes de reflorestamento, de acordo com relatos do proprietário. E 18 espécies nativas foram comuns às duas áreas, provenientes da regeneração natural (Tabela 1).

As famílias mais representativas quanto ao número de espécies foram Fabaceae com 23, seguida de Myrtaceae com 06, Malvaceae e Meliaceae com 05, Anacardiaceae, Bignoniaceae, Euphorbiaceae e Sapindaceae com 04, Rutaceae com 03. Nestas famílias estão contidos 69,05\% das espécies (Figura 2).

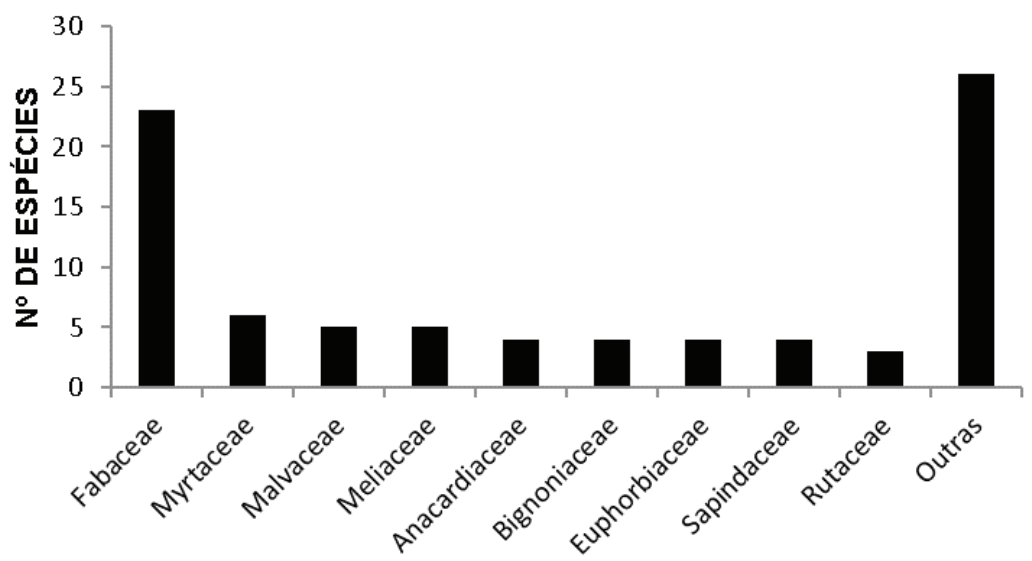

FAMÍLIAS

Figura 2. Famílias de maior riqueza específica coletadas no período de dezembro de 2010 a março de 2011, no Ribeirão da Içara, distrito de Içara, município de Astorga, Paraná.

A representatividade das famílias Fabaceae, Myrtaceae, Rutaceae, Meliaceae, Euphorbiaceae, confirma a importância dessas em florestas ciliares de domínio Semidecidual (SILVA; SOARES, 2003; VEIGA et al., 2003; BORGHI et al., 2004; BATTILANI et al., 2005; SOUZA; MONTEIRO, 2005; CAMPOS et al., 2006; BUENO et al., 2007; SOUZA et al., 2007). 
Fabaceae representada por 23 espécies foi a de maior riqueza, com 27,38\% das espécies amostradas, sendo que Mimosoideae com 09, Caesalpinioideae ocorreu com 08 espécies e Faboideae com 06.

A família Fabaceae é considerada a terceira maior das angiospermas, compreendendo cerca de 727 gêneros e 19.327 espécies, 36 tribos e 03 subfamílias (LEWIS et al., 2005). E, de acordo com Gusson et al. (2008), a Fabaceae se destaca por sua importância atribuída à função na fixação de nitrogênio no ecossistema, a partir das interações mutualísticas com os microorganismos do solo, podendose inferir que influenciam no desenvolvimento das espécies pioneiras, facilitando a entrada destas em estágios sucessionais mais avançados.

As famílias Annonaceae, Boraginaceae, Cannabaceae, Lauraceae, Moraceae, Phytolaccaceae e Urticaceae apresentaram apenas duas espécies cada, contribuindo com 16,66\%. Já as famílias Apocynaceae, Celastraceae, Erythroxylaceae, Nyctaginaceae, Polygonaceae, Proteaceae, Rhamnaceae, Rubiaceae, Salicaceae, Sapotaceae, Solanaceae e indeterminada apresentaram apenas uma espécie cada, contribuindo com $14,28 \%$ das espécies.

O gênero com maior número de espécies foi o Machaerium, com três. Dentre os demais, 05 foram representados por duas espécies e 78 por uma. Machaerium é um gênero que apresenta uma grande riqueza específica na maioria dos trabalhos florísticos, com ampla distribuição (MENDONÇA FILHO; TOZZI; MARTINS, 2007).

Dentre as espécies, foram verificadas dez espécies exóticas: Azadirachta indica (nim), Eucalyptus sp, Grevillea robusta (grevílea), Hovenia dulcis (uva-japonesa), Leucaena leucocephala (leucena), Mangifera indica (mangueira), Melia azedarach (santa-bárbara), Psidium guajava (goiaba-vermelha), Spondias dulcis (cajá-manga), Syzygium cumini (jambolão).

Segundo Ziller (2001), o processo de invasão de um ecossistema por planta exótica ocorre quando uma espécie não natural de um ecossistema é introduzida nele e se naturaliza, de maneira a se dispersar e alterar o mesmo. Tal potencial em alterar ecossistemas é tamanho, sendo considerada a segunda maior ameaça mundial à biodiversidade, perdendo apenas para a destruição dos hábitats por ações antrópicas.

Dessa forma, um exemplo de espécie exótica é a Hovenia dulcis, arbórea invasora que ocupa espaços de espécies nativas, impedindo a evolução sucessional 
da floresta, implicando na diversidade biológica e também possui regeneração abundante no sub-bosque da floresta (HORUS, 2011).

Segundo Souza (1998) a paisagem da Floresta Estacional Semidecidual apresenta-se muito diversificada devido às manchas provocadas pelos diferentes tipos e graus de perturbações, resultantes de cortes seletivos, pisoteio do gado, trilhas e incêndios.

Quanto ao estágio sucessional, 35,93\% (23) das espécies pertencem à classe das pioneiras; 32,81\% (21) das secundárias iniciais; 20,31\% (13) à classe das secundárias tardias; e 10,44\% (07) são clímax (Tabela 1; Figura 3), indicando que a mata ciliar apresenta estágio sucessional com predomínio de pioneiras e secundárias, mostrando que possivelmente está ocorrendo processo de aumento da diversidade de espécies.

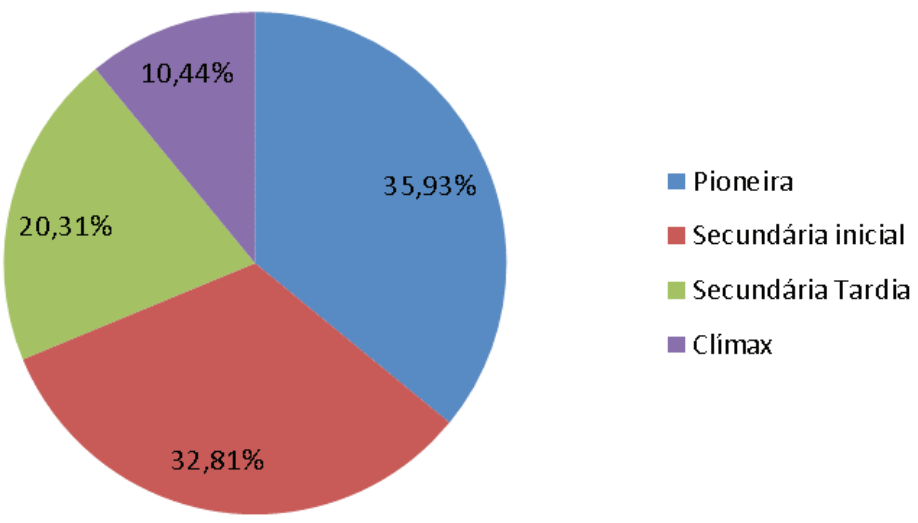

Figura 3. Porcentagem de espécies distribuídas de acordo com o estágio sucessional na mata ciliar do Ribeirão da Içara, no município de Astorga, Paraná.

Desta forma, confirma-se que existe uma substituição gradual das categorias sucessionais, de maneira que nos estágios iniciais predominam indivíduos intolerantes à sombra e, à medida que o processo evolui, espécies tolerantes à sombra passam a ter um papel importante no remanescente florestal (VACCARO, 1997). 
Já as espécies classificadas como clímax, encontradas na área de mata ciliar, são típicas de Floresta Estacional Semidecidual, pois a grande representatividade de espécies pioneiras e secundárias pode ser um indicador de fragmentação e desmatamento intensivo (BORGHI et al., 2004; CAMPOS, 2006).

Das espécies ocorrentes na mata ciliar, quatro constam na lista vermelha da flora do Paraná, consideradas em extinção, sendo classificadas como raras o Machaerium paraguariensi e Myrocarpus frondosus, baixo risco a Solanum granuloso-leprosum e a Cedrela fissilis em perigo (Tabela 1).

\section{CONSIDERAÇÕES FINAIS}

A presença de espécies nativas mostra que a área de mata ciliar, mesmo com impactos causados por ações antrópicas, conserva espécies importantes para o local, e que essas espécies devem ser preservadas, garantindo a diversidade do local. Além disso, vale ressaltar que essas espécies encontram-se no bioma de Mata Atlântica, que está entre os cinco primeiros ecossistemas mais ameaçados do mundo, e que principalmente no Estado do Paraná passa por sérios problemas de impactos ambientais.

Além disso, a presença de espécies da flora ameaçadas de extinção reforça a necessidade de preservação da área de mata ciliar. Devido à importância da vegetação de mata ciliar para a manutenção dos ecossistemas, mesmo que pequenos e isolados, são importantes potenciais fontes de propágulos, dispersores e polinizadores para o estabelecimento de faixas de vegetação.

Com isso, estudos florísticos são importantes para conhecer o funcionamento do mesmo e assim ajudar no manejo e conservação dos mesmos, que podem ser desenvolvidos através de programas de restauração ecológica, controle das espécies exóticas e invasoras e corredores de biodiversidade. 


\section{REFERÊNCIAS}

ALCALÁ, M.; FRANCESCHI, N. C. S.; STRANGHETTI, V. Florística de trechos de matas ciliares do ribeirão Borá e ribeirão Cubatão, Potirendaba - SP. Rev. Inst. Flor., São Paulo, v. 18, p. 79-93, 2006.

APG III. An update of the Angiosperm Phylogeny Group classification for the orders and families of flowering plants: APG III. Botanical Journal of the Linnean Society, v. 161, p. 105-121, 2009.

BARBOSA, L. M. Considerações gerais e modelos de recuperação de formações ciliares. In: RODRIGUES, R. R.; LEITÃO FILHO, H. de F. (Ed). Matas ciliares: conservação e recuperação. São Paulo: Ed. da Universidade de São Paulo, Fapesp, 2000. p. 299-312.

BATTILANI, J. L.; SCREMIN-DIAS, E.; SOUZA, A. L. T. Fitossociologia de um trecho da mata ciliar do rio da Prata, Jardim, MS, Brasil. Acta Botânica Brasilica, v. 19, n. 3, p. 597-608, 2005.

BORGHI, W. A.; MARTINS, S. S.; QUIQUI, E. M. D.; NANNI, M. R. Caracterização e avaliação da mata ciliar à montante da Hidrelétrica de Rosana, na Estação Ecológica do Caiuá, Diamante do Norte, PR. Cad. biodivers. v. 4, n. 2, dez. 2004.

BRASIL. Lei $\mathrm{n}^{\circ}$ 4.771, de 15 de setembro de 1965. Novo Código Florestal. Diário Oficial, Brasília, DF, 16 set. 1965. Disponível em: <http:/www.planalto.gov.br/ ccivil_03/LEIS/L4771.htm>. Acesso em: 10 mar. 2010.

BRASIL. Lei n ${ }^{0} 11.428$, de 22 de dezembro de 2006. Utilização e proteção da vegetação nativa do Bioma Mata Atlântica. Diário Oficial, Brasília, DF, 22 de dezembro de 2006. Disponível em: < http://www.planalto.gov.br/ccivil_03/_ato20042006/2006/ lei/111428.htm > . Acesso em: 25 mar. 2011.

BUENO, M. L.; RESENDE, U. M.; GOMES, T. R. Levantamento florístico nas trilhas turísticas da RPPN São Geraldo, Bonito, Mato Grosso do Sul. Revista Brasileira de Biociências, Porto Alegre, v. 5, supl. 2, p. 189-191, 2007. 
BUDOWSKI, G. Distribution of tropical American rain forest species in the light of successional processes. Turrialba, v. 15, p. 40-42, 1965.

CAMPOS, J. B. A fragmentação de ecossistemas, efeitos decorrentes e corredores de biodiversidade. In: CAMPOS, J. B.; TOSSULINO, M. de G. P.; MULLER, C. R. C. (Org.). Unidades de conservação: ações para a valorização da biodiversidade. Curitiba: Instituto Ambiental do Paraná, 2006. p. 165-173.

CAMPOS, E. P.; SILVA, A. F.; MEIRA NETO, J. A. A.; MARTINS, S. V. Florística e Estrutura horizontal da vegetação arbórea de uma ravina em um fragmento florestal no Município de Viçosa, MG. Rev. Árvore, Viçosa-MG, v. 30, n. 6, p. 1045-1054, 2006.

CARPANEZZI, A. A. P.; CARPANEZZI, O. T. Espécies nativas recomendadas para recuperação ambiental no estado do Paraná, em solos não degradados. Colombo, PR: Embrapa - Empresa Brasileira de Pesquisa Agropecuária. Embrapa Florestas, Ministério da Agricultura e do Abastecimento, 2006. (Documentos 136)

CARVALHO, P. E. R. Espécies arbóreas brasileiras. Brasília: Embrapa Informação Tecnológica, Colombo, Embrapa Floresta, 2003. v. 1.

DEL QUIQUI, E. M.; MARTINS, S. S.; SILVA, I. C.; BORGHI, W. A.; SILVA, O. H.; SAKURAGUI, C. M.; PACHECO, R. B. Estudo fitossociológico de um trecho da floresta estacional semidecidual em Diamante do Norte, Estado do Paraná, Brasil. Acta Scientiarum Agronomy, Maringá, v. 29, n. 2, p. 283-290, 2007.

DURIGAN, G.; SILVEIRA, É. R. Recomposição da Mata Ciliar em domínio de Cerrado, Assis, SP, Brasil. Rev. Scientia Forestalis, n. 56, p. 135-144, 1999.

EMBRAPA. Empresa Brasileira de Pesquisa Agropecuária. Atlas do meio ambiente do Brasil. 2. ed., rev. aum. Brasília: EMBRAPA - SPI, Terra Viva, 1999.

FERRETTI, A. R.; KAGEYAMA, P. Y.; ARBOEZ, G. F.; SANTOS, J. D.; BARROS, M. I. A.; LORZA, R. F.; OLIVEIRA, C. Classificação das espécies arbóreas em grupos ecológicos para revegetação com nativas no estado de São Paulo. Rev. Florestar Estatístico, São Paulo, v. 3, n. 7, 1995. 
FIDALGO, O.; BONONI, V. L. R. Técnicas de coleta, preservação e herborização de material botânico. São Paulo: Instituto de Botânica/Governo do Estado de São Paulo/Secret. do Meio Ambiente, 1989.

FLORA DIGITAL RS. Laboratório de Fitoecologia e Fitogeografia. 2008. Disponível em: <http://www6.ufrgs.br/fitoecologia/florars. > Acesso em: 16 jul. 2011.

FONTOURA, R. Biodiversidade: conceitos e práticas para a conservação. PARANÁ Secretaria de Estado do Meio Ambiente e Recursos Hídricos. Curitiba: [s.n.], p. 1144, 2007. 79 p.

FUNVERDE. Fundação verde plantando um mundo melhor. Disponível em: < http://funverde.wordpress.com/about/manual-de-recuperacao-de-mata-ciliar/ $>$. Acesso em: 04 jun. 2011.

GANDOLFI, S. Estudo florístico e fitossociológico de uma floresta residual na área do Aeroporto Internacional de São Paulo, município de Guarulhos, SP. Dissertação de mestrado, Instituto de Biologia, Universidade Estadual de Campinas.1991. 232p.

GASPARINO, D.; MALAVASI, U. C.; MALAVASI, M. M.; SOUZA, I. Quantificação do banco de sementes sob diferentes usos do solo em área de domínio ciliar. Rev. Árvore, Viçosa-MG, v. 30, n. 1, p. 1-9, 2006.

GOOGLE EARTH. Software. Disponível em: < http://www.google.com/earth/index. html>. Acesso em: 11 jun. 2011.

GUSSON, A. E.; LOPES, S. F.; OLIVEIRA, A. P.; VALE, V. S.; DIAS NETO, O. C.; SCHIAVINI, I. A Família Fabaceae nas Florestas Estacionais Semideciduais do Triângulo Mineiro. In: SIMPÓSIO NACIONAL CERRADO. II SIMPÓSIO INTERNACIONAL SAVANAS TROPICAIS, PARLAMUNDI, 9., 2008, Brasília, DF. Anais... 2008.

HORUS. Instituto Horus de Desenvolvimento e Conservação Ambiental. Disponível em: < http://www.institutohorus.org.br/> Acesso em: jun. 2011.

IAP. Instituto Ambiental do Paraná Lista Oficial de espécies exóticas invasoras para o estado do Paraná. Portaria IAP n 074, de 19 de abril de 2007. 
Disponível em: <http://celepar7.pr.gov.br/sia/atosnormativos/form_cons_ato1. asp?Codigo =1966> . Acesso em: 12 jun. 2011.

IBGE. Biblioteca digital do IBGE. Coleções digitais: mapas. Disponível em: < http:// biblioteca.ibge.gov.br/visualizacao/mapas/GEBIS\%20-\%20RJ/SF-22-Y-D-II-2.jpg > . Acesso em: 08 ago. 2011.

IBGE. Mapas de bioma e de vegetação. 21 de maio de 2004. Disponível em: http://www.ibge.gov.br/home/presidência/noticias/noticia_visualiza.php?id_ noticia $=169 \&$ \&d_pagina $=1$. Acesso em: 25 maio 2011 .

IBGE. Manuais técnicos em geociências: Manual técnico da vegetação brasileira. Rio de Janeiro: CCDI/Departamento de editoração gráfica e científica, nov/1992.

IPNI. The International Plant Names Index. 2011. Disponível em: < http://www. ipni.org/ipni/plantnamesearchpage.do > . Acesso em: 10 maio 2011.

IUCN 2010. IUCN Red List of Threatened Species. IUCN 2010. IUCN Lista Vermelha de Espécies Ameaçadas. Version 2010.1. Versão 2.010,1. < http://www.iucnredlist. org $>$. < http://www.iucnredlist.org $>$. Downloaded on 11 March 2010. Acesso em: 27 abr. 2010.

KAGEYAMA, P. Y. Recomposição da vegetação com espécies nativas em reservatórios de usinas hidrelétricas da CESP. Série Técnica IPEF, v. 28, n. 25, p. 1-43, 1992.

LEITAO FILHO, H. F. Considerações sobre a florística de florestas tropicais e subtropicais do Brasil. IPEF, Piracicaba, v. 35, p. 41-46, 1987.

LEWIS, G.; SCHRIRE, B.; MACKINDER, B.; LOCK, M. Legumes of the World. The Royal Botanic Gardens, Kew, 2005. 577p.

LORENZI, H. Plantas daninhas do Brasil: terrestres, aquáticas, parasitas e toxicas. 3. ed. Nova Odessa, SP: Instituto Plantarum, 2000. 642p.

LORENZI, H. Árvores brasileiras: manual de identificação e cultivo de plantas arbóreas do Brasil. 5. ed. Nova Odessa, SP: Instituto Plantarum, 2008. v. 1. 
LORENZI, H. Árvores brasileiras: manual de identificação e cultivo de plantas arbóreas do Brasil. 3. ed. Nova Odessa, SP: Instituto Plantarum, 2009a. v. 2.

LORENZI, H. Árvores brasileiras: manual de identificação e cultivo de plantas arbóreas nativas do Brasil. Nova Odessa, SP: Instituto Plantarum, 2009b. v. 3.

MARANGON, L. C.; SOARES, J. J.; FELICIANO, A. L. P. Florística arbórea da Mata da Pedreira, município de Viçosa, Minas Gerais. Rev. Árvore, v. 27, n. 2, p. 207-215, 2003.

MARTINS, S. S. Recomposição de matas ciliares no Estado do Paraná. 2. ed. rev. e atual. Maringá: Clichetec, 2005. 32p.

MENDONÇA FILHO, C. V.; TOZZI, A. M. G. A.; MARTINS, E. R. F. Revisão taxonômica de Machaerium sect. Oblonga (Benth.) Taub. (Leguminosae, Papilionoideae, Dalbergieae). Rev. Rodriguésia, Campinas, v. 58, n. 2, p. 283-312, 2007.

METZGER, J. P. Como restaurar a conectividade de paisagens fragmentadas? In: KAGEYAMA, P. Y.; OLIVEIRA, R. E. de; MORAES, L. F. de; ENGEL, V. L.; GANDARA, F. B. (Org.). Restauração ecológica de ecossistemas naturais. Botucatu: FEPAF, 2003. p. $49-76$.

MOBOT. Missouri Botanical Garden. 2008. Disponível em: < http://www.tropicos. org > . Acesso em: maio 2011.

NEOTROPICAL HERBARIUM SPECIMES. The Field Museum, 1999. Disponível em: $<$ http://fm1.fieldmuseum.org/vrrc/> . Acesso em: jan. fev. mar. maio ago. 2011.

PARANÁ. Atlas Geográfico do Estado do Paraná: o uso de novas tecnologias. Curitiba, PR: Secretaria do Estado da Educação do Paraná; Instituto de Terras, Cartografias e Florestas, 2007.

RODERJAN, C. V.; KUNIYOSHI, Y. S.; GALVÃO, F. As regiões fitogeográficas do Estado do Paraná. Acta Forestalia Brasiliensis, Curitiba, v. 1, p. 3-7, 1998.

SANCHEZ, M.; PEDRONI, F.; LEITÃO-FILHO, H. F.; CESAR, O. Composição florística de um trecho de floresta ripária na Mata Atlântica em Picinguaba, Ubatuba, SP. 
Revista Brasileira de Botância, v. 22, n. 1, p. 31-42, 1999.

SEMA. Secretaria do Meio Ambiente do Estado do Rio Grande do Sul. 2002. Disponível em: < http://www.sema.rs.gov.br/sema/html/mataciliar.ht. > . Acesso em: 09 abr. 2009.

SILVA, L. A.; SOARES, J. J. Composição florística de um fragmento de floresta estacional semidecídua no município de São Carlos-SP. Revista Árvore, v. 27, n. 5, p. 647-656, 2003.

SOARES-SILVA, L. H.; SILVA, F. C.; CAVALHEIRO, A. L. Inventário Florístico e Revitalização do Bosque da Associação dos Funcionários Municipais de Londrina. Brasil Florestal, Brasília, v. 20, n. 70, p. 22-31, 2001.

SOS MATA ATLÂNTICA. Fundação SOS Mata Atlântica: flora. Disponível em: $<$ http://www.sosmatatlantica.org.br/index.php?section $=$ info\&action =flora $>$. Acesso em: 10 dez. 2010.

SOUZA, V. C.; LORENZI, H. Botânica Sistemática: Guia ilustrado para identificação das famílias de Fanerógamas nativas e exóticas no Brasil, baseado em APG II. 2. ed. Nova Odessa, SP: Instituto Plantarum, 2008.

SOUZA, M. C. Estrutura e composição florística da vegetação de um remanescente florestal da margem esquerda do Rio Paraná (Mata do Araldo, Município de Porto Rico, PR). UNESP. 1998. 172f. Tese (Doutorado em Ciências Biológicas, área de Biologia Vegetal) - Instituto de Biociências do Campus de Rio Claro. Universidade Estadual Paulista, 1998.

SOUZA, F. N.; ARAÚJO, E. J. G.; MELLO, J. M.; SCOLFORO, J. R. S.; SILVA, C. P. C. Composição Florística e Estrutura de Dois Fragmentos de Floresta Estacional Semidecidual na Bacia do Rio Grande, Minas Gerais. Revista Brasileira de Biociências, Porto Alegre, v. 5, p.183-185, 2007.

SOUZA, M. C.; MONTEIRO, R. Levantamento florístico em remanescente de floresta ripária no alto rio Paraná: Mata do Araldo, Porto Rico, Paraná, Brasil. Acta Scientarum. Biological Sciences, Maringá, v. 27, n. 4, p. 405-414, 2005. 
VACCARO, S. Caracterização Fitossociológica de três fases sucessionais de uma Floresta Estacional Decidual, no Município de Santa Tereza-RS. Santa Maria. 1997. 104f. Tese (Mestrado em Engenharia Florestal, área de Silvicultura) Universidade Federal de Santa Maria, RS-Brasil, 1997.

VEIGA, M. P.; MARTINS, S. S.; SILVA, I. C.; TORMENTA, C. A.; SILVA, O. H. Avaliação dos aspectos florísticos de uma mata ciliar no Norte do Estado do Paraná. Acta Scientiarum. Agronomy, Maringá, v. 25, n. 2, p. 519-525, 2003.

ZILLER, S. R. Plantas exóticas invasoras: a ameaça da contaminação biológica. Rev. Ciência Hoje. v. 30, n. 178, p. 77-79, 2001.

Recebido em: 24 de setembro de 2013 Aceito em: 16 de junbo de 2014 